\section{OPEN ACCESS}

Edited by:

Adriana Modesto Vieira, University of Pittsburgh, United States

Reviewed by:

Sivakumar Nurvula,

Narayana Dental College and

Hospital, India

Varinder Goyal,

Guru Nanak Dev Dental College \&

Research Institute, India

Alexandre Rezende Vieira,

University of Pittsburgh, United States

${ }^{*}$ Correspondence:

Christian Kirschneck

christian.kirschneck@

klinik.uni-regensburg.de

Specialty section:

This article was submitted to

Pediatric Dentistry,

a section of the journal

Frontiers in Dental Medicine

Received: 30 April 2021

Accepted: 12 July 2021

Published: 09 August 2021

Citation:

Reis CLB, Barbosa MCF, de Lima DC, Madalena IR, Baratto-Filho F, Proff $P$,

de Oliveira DSB, Paddenberg E,

Küchler EC and Kirschneck C (2021)

Study of Dental Caries and PTH Gene.

Front. Dent. Med. 2:703549.

doi: 10.3389/fdmed.2021.703549

\title{
Study of Dental Caries and PTH Gene
}

\section{Caio Luiz Bitencourt Reis ${ }^{1}$, Mariane Carolina Faria Barbosa ${ }^{2}$, Daniela Coelho de Lima ${ }^{3}$, Isabela Ribeiro Madalena ${ }^{1,4,5}$, Flares Baratto-Filho ${ }^{4}$, Peter Proff ${ }^{6}$, Daniela Silva Barroso de Oliveira ${ }^{3}$, Eva Paddenberg ${ }^{6}$, Erika Calvano Küchler ${ }^{6}$ and Christian Kirschneck ${ }^{6 *}$}

${ }^{1}$ Department of Pediatric Dentistry, School of Dentistry of Ribeirão Preto, University of São Paulo, São Paulo, Brazil, 2 Department of Child and Adolescent Health, School of Dentistry, Federal University of Minas Gerais, Belo Horizonte, Brazil, ${ }^{3}$ Department of Clinic and Surgery, School of Dentistry, Federal University of Alfenas, Alfenas, Brazil, ${ }^{4}$ Department of Dentistry, University of the Region of Joinville, Joinville, Brazil, ${ }^{5}$ Department of Restorative Dentistry, Federal University of Juiz de Fora, Belo Horizonte, Brazil, ${ }^{6}$ Department of Orthodontics, University of Regensburg, Regensburg, Germany

Parathyroid hormone $(\mathrm{PTH})$ is essential for calcium and phosphate homeostasis in odontogenesis-related cells. Therefore, the present study aimed to investigate the association between single nucleotide polymorphisms in the gene encoding $\mathrm{PTH}$, and dental caries in Brazilian children. Three hundred and fifty-three children (170 boys and 183 girls, age ranging from 8 to 11 years old) were included in this study. The International System for Detection and Assessment of Carious Lesions (ICDAS) was used for diagnosis of dental caries. Visible biofilm was also evaluated during the clinical examination. Genomic DNA was extracted from saliva for real-time PCR to evaluate the single nucleotide polymorphisms rs6256, rs307247 and rs694 in PTH gene. Dental caries was classified in ICDAS 0 vs. ICDAS I-6 $_{1}$ or ICDAS ${ }_{1-2}$ vs. ICDAS ${ }_{3-6}$. Chi-square test, binary logistic regression adjusted by biofilm and haplotype analyses were performed $(p<0.05)$. Biofilm was associated with dental caries $(p<0.05)$. There were no associations between dental caries and rs6256, rs307247, rs694 in none of the analyses performed ( $p>0.05$ ). In conclusion, the present study supports that the single nucleotide polymorphisms rs6256, rs307247, and rs694 in the PTH-encoding gene are not associated with dental caries in Brazilian children.

Keywords: dental caries, parathyroid hormone, polymorphism, single nucleotid polymorphism, children

\section{INTRODUCTION}

Parathyroid hormone (PTH) is essential for many biological processes, mostly for regulating extracellular fluid calcium and phosphate homeostasis (1). PTH is the product of chief cells of parathyroid glands in response to low calcium serum levels (2) and initiates a mechanism of bone resorption to stimulate calcium release (3). Besides that, $\mathrm{PTH}$ is involved in a complex interaction network in proliferation of mesenchymal stem cells and enhances the differentiation of osteo- and odontogenesis-related cells (4). Odontogenesis is a highly coordinated process of tooth formation and morphogenesis. This process relies upon protein-cell interaction, in which odontoblasts and ameloblasts are the cells responsible for dentin and enamel synthesis (5). PTH play a direct role in odontoblast and ameloblast $(6,7)$. Interestingly, during tooth formation, any imbalance in this 
network of protein-cell interaction may impacts dental tissues (8). This fact may lead to an enamel and dentin defects, contributing to an increased susceptibility risk and progression of dental caries $(8,9)$.

Dental caries is a multifactorial disease characterized by the demineralization of tooth minerals. It is one of the most common chronic diseases during childhood (10). The link between dental caries and host genetic background has been constantly studied due to the possibility that some genes may interfere in the function of amelogenesis and dentinogenesis related proteins and predicted the susceptibility or progression to dental caries (11). However, the association between dental caries and variants in PTH decoder gene was little investigated in children $(12,13)$.

Single nucleotide polymorphisms (SNPs) are a type of sequence variation within genomes that may modify the function and the quantity of protein expression. In fact, previous studies demonstrated that SNPs in PTH gene were associated with modifications of PTH serum levels (14-17). These modifications in PTH serum levels may both influence tooth formation and the remineralization and demineralization equilibrium of the tooth in occlusion $(2,18)$. Thus, it is possible that SNPs in PTH are involved in the risk of dental caries. Therefore, the present study aimed to investigate the association between SNPs rs6256, rs307247, rs694 in the gene encoding $\mathrm{PTH}$, and dental caries in Brazilian children.

\section{MATERIALS AND METHODS}

This study was designed and reported according to the Strengthening the Reporting of Genetic Association study (STREGA) statement checklist. After the consent by the Local Human Ethics committee (protocol: 78568217.7.0000.5142), this cross-sectional study recruited biologically unrelated schoolchildren of both genders, aged between 8 and 11 years, enrolled in schools in the city of Alfenas, Brazil. Parents/legal guardians agreed to participate in written informed consent and an assent document was developed for children. All standard biosecurity and institutional safety procedures have been adhered in this study. Children with unhealthy systemic conditions, diseases, endocrinal problems or hormonal treatment, and children with syndromes were excluded. This sample was previously described in Reis et al. (19).
A sample size calculation was performed [power $=80 \%$; alpha $=95 \%$; effect size (Cohen's $w$ ) $=0.20$; Degrees of freedom: 3] and predicted a minimum of 273 children. The sample and data collection were performed in 2018 by one single examiner trained and calibrated (Kappa intra-examiner $=$ 0.87). Information about health habits was obtained through the anamnesis answered by parents or caregivers.

Dental caries was accessed by ICDAS (International Caries Detection and Assessment System) according to Shoaib et al. (20). ICDAS was categorized as a dichotomic variable in two different cut-offs: Healthy $\left(\mathrm{ICDAS}_{0}\right)$ vs. Caries $\left(\mathrm{ICDAS}_{1-6}\right)$; or non-cavitated lesion $\left(\mathrm{ICDAS}_{1-2}\right)$ vs. cavitated caries lesion $\left(\mathrm{ICDAS}_{3-6}\right)$, as previously described (21).

Visible biofilm was also evaluated using the index described by Silness and Löe (22). The scores vary from 0 (absence) to 3 (abundant on the surface of the tooth).

For the genotyping analysis DNA samples from each child were used. Briefly, genomic DNA was isolated from buccal/oral epithelial cells in saliva samples and extracted from saliva following a pre-established protocol (23). The saliva tube was centrifuged and supernatant was discarded. Extraction solution (Tris- $\mathrm{HCl} 10 \mathrm{mmol} / \mathrm{L}$, pH 7.8; EDTA 5 mmol/L; SDS 0.5\%, $1 \mathrm{~mL}$ ) and proteinase $\mathrm{K}(100 \mathrm{ng} / \mathrm{mL})$ was added to the tube. Afterwards, for removal of non-digested proteins, ammonium acetate was added and centrifugation performed. The DNA was precipitated with isopropanol and washed with $70 \%$ ethanol. The tubes were allowed to air-dry on an absorbent paper and DNA resuspended in $100 \mu \mathrm{L}$ of TE buffer $(10 \mathrm{mmol} / \mathrm{L}$ Tris $(\mathrm{pH} 7.8)$ and $1 \mathrm{mmol} / \mathrm{L}$ EDTA). The concentration and purity of DNA was determined by spectrophotometry using NanoDrop 1000 (Thermo Scientific, Wilmington, DE, EUA).

Genotyping was performed by Real-time polymerase chain reactions (PCR) using TaqMan probes (Applied Biosystems ${ }^{\circledR}$, 7500 Real-Time PCR System, Thermo Fisher Scientific). The allelic discrimination real-time PCR reactions were performed in a total volume of $5 \mu \mathrm{L}$ (5 ng DNA/reaction in $\mathrm{H}_{2} \mathrm{O}, 2.5$ $\mu \mathrm{L}$ TaqMan PCR master mix, $0.125 \mu \mathrm{L}$ SNP assay; Applied Biosystems). The thermal cycling was carried out by starting with a hold cycle of $95^{\circ} \mathrm{C}$ for $10 \mathrm{~min}$, followed by 40 amplification cycles of $92^{\circ} \mathrm{C}$ for $15 \mathrm{~s}$ and $60^{\circ} \mathrm{C}$ for $1 \mathrm{~min}$. The SNPs selected in this study were previously associated with alterations in $\mathrm{PTH}$ serum level (14-16). Characteristics of the SNPs in the PTH gene are summarized in Table $\mathbf{1}$.

TABLE 1 | Characteristics of studied SNPs in PTH gene.

\begin{tabular}{|c|c|c|c|}
\hline SNP & rs6256 & rs307247 & rs694 \\
\hline Position & 13492506 & 13491931 & 13492870 \\
\hline Function & Stop Gained (Arg > Stop codon) & Downstream Variant & Intron Variant \\
\hline $\mathrm{MAF}^{\#}$ & 0.12 & 0.41 & 0.39 \\
\hline Base change & $\mathrm{T}>\mathrm{G}$ & $G>A$ & $\mathrm{~T}>\mathrm{C}$ \\
\hline $\begin{array}{l}\text { Function } \\
\text { (Reference) }\end{array}$ & $\begin{array}{l}\text { Minor allele decreases PTH serum } \\
\text { levels } \\
(14)\end{array}$ & $\begin{array}{l}\text { Minor allele decreases PTH serum } \\
\text { levels } \\
\text { (15) }\end{array}$ & $\begin{array}{l}\text { Minor allele decreases PTH serum } \\
\text { levels } \\
(16)\end{array}$ \\
\hline
\end{tabular}

${ }^{\#}$ Minor Allele Frequency. Information was obtained in https://www.ncbi.nlm.nih.gov/snp/. 
TABLE 2 | Gender, age and biofilm distribution between phenotypes.

\begin{tabular}{|c|c|c|c|c|c|c|c|c|c|c|}
\hline \multicolumn{2}{|l|}{ Phenotypes } & \multicolumn{3}{|c|}{ Sex } & \multicolumn{3}{|c|}{ Age } & \multicolumn{3}{|c|}{ Biofilm } \\
\hline & & Male (\%) & Female (\%) & $p$-value* & Mean & $\mathbf{S D}^{\#}$ & $p$-value ${ }^{t}$ & Mean & SD & $p$-value ${ }^{t}$ \\
\hline \multirow[t]{2}{*}{ Healthy vs. Dental caries } & $I_{C D A S}$ & $92(48.7)$ & 97 (51.3) & 0.48 & 8.95 & 0.92 & 0.47 & 1.75 & 0.30 & 0.0001 \\
\hline & $\mathrm{ICDAS}_{1-6}$ & 78 (47.6) & $86(52.4)$ & & 8.79 & 0.84 & & 1.83 & 0.26 & \\
\hline \multirow{2}{*}{$\begin{array}{l}\text { Healthy and non-cavitated caries lesion vs. Cavitated } \\
\text { caries lesion }\end{array}$} & $\mathrm{ICDAS}_{0-2}$ & 98 (48.3) & 105 (51.7) & 0.83 & 8.92 & 0.81 & 0.87 & 1.74 & 0.30 & 0.007 \\
\hline & $\mathrm{ICDAS}_{3-6}$ & 72 (48.0) & 78 (52.0) & & 8.83 & 0.95 & & 1.85 & 0.24 & \\
\hline
\end{tabular}

${ }^{*}$ Chi-square test. ${ }^{\#}$ Standard Deviation. ${ }^{\dagger}$ Student's T test. Bold forms mean p-values $<0.05$.

TABLE 3 | Allele and haplotype analysis.

\begin{tabular}{|c|c|c|c|c|c|c|c|}
\hline \multirow[t]{2}{*}{ SNPs } & \multirow[t]{2}{*}{ Minor allele } & \multicolumn{3}{|c|}{ Frequencies of ICDAS0 vs. ICDAS1-6 } & \multicolumn{3}{|c|}{ Frequencies of ICDAS0-2 vs. ICDAS3-6 } \\
\hline & & Control & Cases & $p^{\#}$ & Control & Cases & $p^{\#}$ \\
\hline rs6256 & $\mathrm{T}$ & 0.13 & 0.16 & 0.358 & 0.13 & 0.17 & 0.210 \\
\hline rs307247 & A & 0.38 & 0.36 & 0.632 & 0.38 & 0.36 & 0.782 \\
\hline \multirow[t]{2}{*}{ rs694 } & C & 0.47 & 0.45 & 0.618 & 0.47 & 0.45 & 0.728 \\
\hline & Haplotypes & Control & Cases & $p^{\star}$ & Control & Cases & $p^{\star}$ \\
\hline \multirow[t]{4}{*}{ rs6256, rs307247 and rs694 } & $G-A-C$ & 0.36 & 0.38 & 0.554 & 0.37 & 0.28 & 0.705 \\
\hline & $T-G-T$ & 0.16 & 0.13 & 0.330 & 0.16 & 0.13 & 0.234 \\
\hline & $G-G-C$ & 0.09 & 0.07 & 0.620 & 0.08 & 0.08 & 0.708 \\
\hline & $G-G-T$ & 0.37 & 0.39 & 0.681 & 0.36 & 0.39 & 0.475 \\
\hline \multirow[t]{3}{*}{ rs6256 and rs694 } & $\mathrm{T}-\mathrm{T}$ & 0.16 & 0.14 & 0.335 & 0.17 & 0.13 & 0.213 \\
\hline & $G-C$ & 0.45 & 0.47 & 0.726 & 0.45 & 0.47 & 0.730 \\
\hline & $G-T$ & 0.37 & 0.38 & 0.724 & 0.36 & 0.39 & 0.570 \\
\hline \multirow[t]{3}{*}{ rs6256 and rs307247 } & $G-A$ & 0.36 & 0.38 & 0.524 & 0.36 & 0.38 & 0.668 \\
\hline & $T-G$ & 0.09 & 0.07 & 0.540 & 0.08 & 0.07 & 0.634 \\
\hline & $G-G$ & 0.54 & 0.53 & 0.779 & 0.54 & 0.53 & 0.878 \\
\hline \multirow[t]{3}{*}{ rs30724 and rs694 } & $A-C$ & 0.36 & 0.38 & 0.618 & 0.36 & 0.38 & 0.680 \\
\hline & $G-C$ & 0.16 & 0.14 & 0.358 & 0.17 & 0.14 & 0.222 \\
\hline & $G-T$ & 0.46 & 0.47 & 0.854 & 0.45 & 0.47 & 0.628 \\
\hline
\end{tabular}

\#PLINK compare the frequencies between the major allele by chi-square test. ${ }^{*} P L I N K$ compare the frequencies between expected number of haplotypes by fisher test.

For statistical analyses, SPSS software version 25.0 (SPSS Inc. Chicago, IL, USA) was used. Chi-square test was applied for evaluating Hardy-Weinberg equilibrium genotypic distribution. Logistic regression adjusted by biofilm was also performed, and alleles and haplotypes were analyzed by PLINK software. A $p<$ 0.05 was considered statistically significant.

\section{RESULTS}

Three hundred and fifty-three children were included in this study, 170 boys (48.2\%) and 183 girls (51.8\%). The mean age of the sample was 8.88 years $(\mathrm{SD}=0.88), 8.82$ years for girls $(\mathrm{SD}=0.81)$, and 8.94 years $(\mathrm{SD}=0.96)$ for boys. Biofilm was significantly more abundant in the ICDAS $_{1-6}$ and ICDAS $_{3-6}$ groups $(p<0.05)$. Detailed information is reported in Table 2.

All studied SNPs were within the Hardy-Weinberg equilibrium $(p>0.05)$. The amplification rate for rs6256 was $97.7 \%(n=345), 94.3 \%$ for $\operatorname{rs} 307247(n=333)$, and $98.0 \%$ for $\operatorname{rs} 694(n=346)$.
Allele distribution and haplotype analysis are shown in Table 3. There was no association between alleles/haplotypes and dental caries $(p>0.05)$.

Dental caries was not associated with any of the SNPs in both comparisons $\left(\mathrm{ICDAS}_{0}\right.$ vs. $\mathrm{ICDAS}_{1-6}$ and $\mathrm{ICDAS}_{0-2}$ vs. ICDAS $_{1-6}$ ) in genotype distribution (Table 4).

Multiple logistic regression adjusted by biofilm was also performed, but the SNPs were not associated with dental caries (Table 5).

ICDAS was also evaluated as a continuous variable, however, no association was also founded in this analysis (data not shown).

\section{DISCUSSION}

To the best of our knowledge, this is the first study to evaluate the association between SNPs in the PTH gene and dental caries in Brazilian children. PTH influences tooth formation, since the odontogenesis-related cells differentiate until dentin and 
TABLE 4 | Genotype distribution between Healthy vs. Dental caries (ICDAS 0 vs. ICDAS ${ }_{1-6}$ ) and Healthy and non-cavitated caries lesion vs. Cavitated caries lesion $\left(\right.$ ICDAS $_{0-2}$ vs. ICDAS $\left.3-6\right)$.

\begin{tabular}{|c|c|c|c|c|c|c|c|c|c|c|c|c|c|c|c|}
\hline \multirow{3}{*}{$\begin{array}{l}\text { SNPS } \\
\text { Genotypes }\end{array}$} & \multicolumn{5}{|c|}{ rs6256 } & \multicolumn{5}{|c|}{ rs307247 } & \multicolumn{5}{|c|}{ rs694 } \\
\hline & $s$ Dominant & eterozygous & $p^{*}$ & Recessive & $p^{\star \#}$ & Dominant & Heterozygous & $p^{*}$ & Recessive & $p^{*}$ & Dominant & Heterozygous & $p^{*}$ & Recessive & $p^{\star}$ \\
\hline & GG (\%) & GT (\%) & & TT (\%) & & GG (\%) & GA (\%) & & AA (\%) & & TT (\%) & TC (\%) & & CC (\%) & \\
\hline $\mathrm{ICDAS}_{0}$ & 135 (55.6) & $50(49.0)$ & 0.266 & $1(100.0)$ & 0.371 & 68 (54.8) & 85 (50.3) & 0.441 & $26(63.4)$ & 0.336 & $49(52.7)$ & 98 (53.3) & 0.928 & $340(57.1)$ & 0.571 \\
\hline $\mathrm{ICDAS}_{1-6}$ & $108(44.4)$ & 52 (51.0) & & $0(0.0)$ & & $56(45.2)$ & $84(49.7)$ & & 15 (36.6) & & 44 (47.3) & $86(46.7)$ & & 30 (42.9) & \\
\hline ICDAS$_{0-2}$ & $146(60.1)$ & $51(50.0)$ & 0.808 & $1(100.0)$ & 0.415 & $592(54.4)$ & 73 (58.9) & 0.449 & 27 (65.9) & 0.185 & 51 (54.8) & 107 (58.2) & 0.598 & 341 (58.6) & 0.634 \\
\hline $\mathrm{ICDAS}_{3-6}$ & 97 (39.9) & $51(50.0)$ & & $0(0.0)$ & & 77 (45.6) & 51 (41.1) & & 14 (34.1) & & $42(45.2)$ & 77 (41.8) & & 29 (41.4) & \\
\hline
\end{tabular}

Chi-square test was performed, except in \#, which was performed Fisher test. *In comparison with dominant genotype.

TABLE 5 | Multiple Logistic Regression adjusted by biofilm.

\begin{tabular}{|c|c|c|c|c|}
\hline SNP & Genotype & Coefficient & OR (CI 95\%) & $p$-value* \\
\hline \multicolumn{5}{|c|}{ Healthy vs. Dental caries $\left(\right.$ ICDAS $_{0}$ vs. ICDAS $\left.{ }_{1-6}\right)$} \\
\hline \multirow[t]{2}{*}{ rs307247 } & GA & 0.277 & $1.32(0.85-2.04)$ & 0.211 \\
\hline & $\mathrm{AA}$ & -0.452 & $0.63(0.31-1.24)$ & 0.193 \\
\hline \multirow[t]{2}{*}{ rs694 } & $\mathrm{TC}$ & 0.100 & $1.10(0.72-1.69)$ & 0.643 \\
\hline & $\mathrm{CC}$ & -0.008 & $0.99(0.41-2.54)$ & 0.985 \\
\hline \multicolumn{5}{|c|}{$\begin{array}{l}\text { Healthy and non-cavitated caries lesion vs. Cavitated caries } \\
\text { lesion }\left(\text { ICDAS }_{0-2} \text { vs. ICDAS }\right. \\
3-6)\end{array}$} \\
\hline \multirow[t]{2}{*}{ rs307247 } & GA & 0.273 & $1.31(0.84-2.05)$ & 0.228 \\
\hline & $\mathrm{AA}$ & -0.352 & 0.70 (0.34-1.39) & 0.324 \\
\hline \multirow[t]{2}{*}{ rs694 } & $\mathrm{TC}$ & -0.043 & $0.95(0.61-1.48)$ & 0.845 \\
\hline & $\mathrm{CC}$ & -0.050 & $0.95(0.54-1.63)$ & 0.855 \\
\hline
\end{tabular}

*In comparison with dominant genotype. The regression was performed with each genotype individually. A complete or quasi-complete data separation made it impossible to analyze the rs6256 SNP.

enamel synthesis $(4,6,7)$. There is evidence that odontoblasts, cementoblasts and ameloblasts, specific cells of tooth formation, express the PTH receptor 1 (PTHR1) and are sensible to PTH serum levels $(7,24)$. Although the effects of PTH on cementoblasts and ameloblasts are not fully understood (24), in vitro studies (7) and studies evaluating PTH-knockout mice (6) indicate that PTH modulates the proliferative and apoptotic responses of odontoblasts, suggesting that modifications in PTH serum levels during odontogenesis can affect dentine and enamel quality and increase the risk and progression of dental caries $(6,7)$. However, more studies should be developed to clarify the function of PTH in ameloblasts and odontoblasts and its impact on dental caries susceptibility and progression.

Although PTH serum levels have been investigated in a variety of conditions (14-17), the relationship between PTH serum levels and dental caries is not clarified yet. While Gyll et al. (25) did not observe differences in PTH serum levels between caries and caries-free children, on the other hand, Schroth et al. (26) and Deane et al. (27) showed an increase in PTH levels in children with Severe Early Childhood Caries, apart from observing a decrease of calcium and 1,25-dihydroxy vitamin $\mathrm{D}$ levels in these children. The authors suggest that changes in PTH levels can unbalance the levels of inflammatory mediators and un-regulate the host's response to dental caries. In fact, by a process not fully understood, the serum levels of some pro-inflammatory proteins, like interleukin-6 (IL-6) and IL-1 $\beta$, are greater in patients diagnosed with primary or secondary hyperparathyroidism, a condition characterized by hypersecretion of PTH $(17,28,29)$. Interestingly, IL6 and IL-1 $\beta$ were already previously associated with dental caries (30-32). Future studies should investigate salivary and serum levels of these inflammatory proteins and PTH to clarify the relationship between $\mathrm{PTH}$ and the process of dental caries.

Calcium and 1,25-dihydroxy vitamin D homeostasis are essential for the formation and maintenance of teeth (33). In fact, low levels of calcium were already associated with dental caries in children $(26,27,34,35)$, as well as low levels of 1,25-dihydroxy vitamin D (36). Low calcium levels are detected by extracellular calcium receptors in the parathyroid glands, which increase PTH gene transcription and secretion. Besides calcium, phosphate and 1,25-dihydroxy vitamin D were also identified to regulate $\mathrm{PTH}$ gene transcription. In bones, PTH stimulates receptor activator for nuclear factor kappa-B ligand (RANKL) expression in osteoblasts, which initiates the differentiation process of immature to mature osteoclasts. This way, calcium is released into the bloodstream by osteoclastic dissolution of organic materials like hydroxyapatite $(37,38)$. Thus, PTH may indirectly interfere in dental caries susceptibility through calcium and vitamin $\mathrm{D}$ regulation.

Our hypothesis was that SNPs in the PTH gene that can alter PTH serum levels would affect tooth-forming tissues and, subsequently, later modify the host's immunoinflammatory response and the calcium regulation (14-17). We speculated that SNPs in the PTH gene may influence the quality/quantity and maintenance of tooth tissues, therefore increasing the susceptibility and risk of progression to dental caries. rs6256, rs307247, and rs694 SNPs were previously associated with a decrease of PTH serum levels (14-17). Besides that, Küchler et al. (39) associated the rs6256, rs307247, and rs694 SNPs in $\mathrm{PTH}$ with mandibular retrognathism in a Brazilian population. In this study, dental caries was not associated with these SNPs. A possible limitation of this study was that inflammatory mediators, calcium, vitamin D, and PTH levels were not 
measured during the formation of the child's dental tissue or during clinical examination.

\section{DATA AVAILABILITY STATEMENT}

The original contributions presented in the study are included in the article/Supplementary Material, further inquiries can be directed to the corresponding author/s.

\section{ETHICS STATEMENT}

The studies involving human participants were reviewed and approved by Human Ethics committe of Federal University of Alfenas (protocol: 78568217.7.0000.5142). Written informed consent to participate in this study was provided by the participants' legal guardian/next of kin.

\section{AUTHOR CONTRIBUTIONS}

CK, EK, DO, FB-F, and DL conceptualize the study. EK, DO, and DL designed and organize the sample recruitment. $\mathrm{MB}$ performed the sample collection and the DNA extraction. CR, $\mathrm{IM}$, and EP performed the genotyping analysis and analyzed the data. CR, MB, EK, and CK wrote the manuscript. EK, PP, CK, and

\section{REFERENCES}

1. Mitra P, Maity B, Pal DK, Das M. Polymorphisms of PTH (Parathyroid hormone) gene and risk of kidney stone disease: a casecontrol study from West Bengal, India. Urology. (2018) 121:79-85. doi: 10.1016/j.urology.2018.06.033

2. Aggarwal P, Zavras A. Parathyroid hormone and its effects on dental tissues. Oral Dis. (2012) 18:48-54. doi: 10.1111/j.1601-0825.2011.01850.x

3. Tokunaga K, Seto H, Ohba H, Mihara C, Hama H, Horibe M, et al. Topical and intermittent application of parathyroid hormone recovers alveolar bone loss in rat experimental periodontitis. J Periodont Res. (2011) 46:655-62. doi: 10.1111/j.1600-0765.2011.01386.x

4. Ge X, Li Z, Jing S, Wang Y, Li N, Lu J, et al. Parathyroid hormone enhances the osteo/odontogenic differentiation of dental pulp stem cells via ERK and P38 MAPK pathways. J Cell Physiol. (2020) 235:1209-21. doi: 10.1002/jcp. 29034

5. Cobourne MT. The genetic control of early odontogenesis. Br J Orthod. (1999) 26:21-8. doi: 10.1093/ortho/26.1.21

6. Sun W, Sun W, Liu J, Zhou X, Xiao Y, Karaplis A, et al. Alterations in phosphorus, calcium and PTHrP contribute to defects in dental and dental alveolar bone formation in calcium-sensing receptor-deficient mice. Development. (2010) 137:985-92. doi: 10.1242/dev.045898

7. Guimaraes GN, Rodrigues TL, de Souza AP, Line SR, Marques MR. Parathyroid hormone (1-34) modulates odontoblast proliferation and apoptosis via PKA and PKC-dependent pathways. Calcif Tissue Int. (2014) 95:275-81. doi: 10.1007/s00223-014-9892-1

8. Conrads G, About I. Pathophysiology of dental caries. Monogr Oral Sci. (2018) 27:1-10. doi: 10.1159/000487826

9. Kirthiga M, Murugan M, Saikia A, Kirubakaran R. Risk factors for early childhood caries: a systematic review and meta-analysis of case control and cohort studies. Pediatr Dent. (2019) 41:95-112.

10. Kassebaum NJ, Bernabé E, Dahiya M, Bhandari B, Murray CJ, Marcenes W. Global burden of untreated caries: a systematic review and metaregression. $J$ Dent Res. (2015) 94:650-8. doi: 10.1177/0022034515573272

11. Opal S, Garg S, Jain J, Walia I. Genetic factors affecting dental caries risk. Aust Dent J. (2015) 60:2-11. doi: 10.1111/adj.12262
FB-F funding support. All authors contributed to the article and approved the submitted version.

\section{FUNDING}

This study was financed in part by the Coordenação de Aperfeiçoamento de Pessoal de Nível Superior - Brasil (CAPES) - Finance Code 001, and Alexander-von-HumboldtFoundation (Küchler/Kirschneck accepted in July 4th, 2019). National Council for Scientific and Technological Development (CNPq) financed individual scholarship.

\section{ACKNOWLEDGMENTS}

Coordenação de Aperfeiçoamento de Pessoal de Nível Superior-Brasil (CAPES), Alexander-von-HumboldtFoundation, and National Council for Scientific and Technological Development (CNPq).

\section{SUPPLEMENTARY MATERIAL}

The Supplementary Material for this article can be found online at: https://www.frontiersin.org/articles/10.3389/fdmed. 2021.703549/full\#supplementary-material

12. Shaffer JR, Wang X, Feingold E, Lee M, Begum F, Weeks, et al. Genomewide association scan for childhood caries implicates novel genes. J Dental Res. (2011) 90:1457-62. doi: 10.1177/0022034511422910

13. Haworth S, Shungin D, Van Der Tas JT, Vucic S, Medina-Gomez C, Yakimov $\mathrm{V}$, et al. Consortium-based genome-wide meta-analysis for childhood dental caries traits. Hum Mol Genet. (2018) 27:3113-27. doi: 10.1093/hmg/ddy237

14. Kanzawa M, Sugimoto T, Kobayashi T, Kobayashi A, Chihara K. Parathyroid hormone gene polymorphisms in primary hyperparathyroidism. Clin Endocrinol. (1999) 50:583-8. doi: 10.1046/j.1365-2265.1999.00685.x

15. Tenne M, McGuigan F, Jansson L, Gerdhem P, Obrant KJ, Luthman H, et al. Genetic variation in the PTH pathway and bone phenotypes in elderly women: evaluation of PTH, PTHLH, PTHR1 and PTHR2 genes. Bone. (2008) 42:719-27. doi: 10.1016/j.bone.2007.12.005

16. Ertl DA, Stary S, Streubel B, Raimann A, Haeusler G. A novel homozygous mutation in the parathyroid hormone gene $(\mathrm{PTH})$ in a girl with isolated hypoparathyroidism. Bone. (2012) 51:629-32. doi: 10.1016/j.bone.2012.06.009

17. Venkatesan S, Chakkarai K, Arulvijayavani S, Senthilkumar GP, Manikandan R, Kalyaperumal M. Association between vitamin D, parathyroid hormone and inflammatory markers in urolithiasis patients. J Renal Inj Prev. (2017) 6:240-3. doi: 10.15171/jrip.2017.45

18. Neel EA, Aljabo A, Strange A, Ibrahim S, Coathup M, Young AM, et al. Demineralization-remineralization dynamics in teeth and bone. Int $J$ Nanomed. (2016) 11:4743-63. doi: 10.2147/IJN.S107624

19. Reis CLB, Barbosa MCF, de Lima DC, Brancher JA, Lopes CMCF, Baratto-Filho F, et al. Risk factors for developmental defects of enamel in children from southeastern Brazil. Community Dent Health. (2021) doi: 10.1922/CDH_00242Reis04. [Epub ahead of print].

20. Shoaib L, Deery C, Ricketts DNJ, Nugent ZJ. Validity and reproducibility of ICDAS II in primary teeth. Caries Res. (2009) 43:442-8. doi: 10.1159/000258551

21. Barbosa MCF, Lima DC, Reis CLB, Reis ALM, Rigo Jr. D, Segato RAB, et al. Vitamin D receptor FokI and BglI genetic polymorphisms, dental caries, and gingivitis. Int J Paediatr Dent. (2020) 30:642-9. doi: 10.1111/ipd.12631

22. Silness J, Loe H. Periodontal disease in pregnancy II. Correlation between oral hygiene and periodontal condition. Acta Odontol Scand. (1964) 22:121-35. doi: $10.3109 / 00016356408993968$ 
23. Küchler EC, Tannure PN, Falagan-Lotsch P, Lopes TS, Granjeiro JM, Amorim LM. Buccal cells DNA extraction to obtain high quality human genomic DNA suitable for polymorphism genotyping by PCR-RFLP and Real-Time PCR. J Appl Oral Sci. (2012) 20:467-71. doi: 10.1590/S1678-775720120004 00013

24. Kato A, Suzuki M, Karasawa Y, Sugimoto T, Doi K. PTHrP and PTH/PTHrP receptor 1 expression in odontogenic cells of normal and HHM model rat incisors. Toxicol Pathol. (2005) 33:456-564. doi: 10.1080/01926230590959604

25. Gyll J, Ridell K, Öhlund I, Åkeson PK, Johansson I, Holgerson PL. Vitamin D status and dental caries in healthy Swedish children. Nutr J. (2018) 17:1-10. doi: 10.1186/s12937-018-0318-1

26. Schroth RJ, Levi JA, Sellers EA, Friel J, Kliewer E, Moffatt ME. Vitamin D status of children with severe early childhood caries: a case-control study. BMC Pediatr. (2013) 13:174. doi: 10.1186/1471-2431-13-174

27. Deane S, Schroth RJ, Sharma A, Rodd C. Combined deficiencies of 25hydroxyvitamin $\mathrm{D}$ and anemia in preschool children with severe early childhood caries: a case-control study. Paediatr Child Health. (2018) 23:e40-5. doi: $10.1093 / \mathrm{pch} / \mathrm{pxx} 150$

28. Emam AA, Mousa SG, Ahmed KY, Al-Azab AA. Inflammatory biomarkers in patients with asymptomatic primary hyperparathyroidism. Med Princ Pract. (2012) 21:249-53. doi: 10.1159/000334588

29. Cheng SP, Liu CL, Liu TP, Hsu YC, Lee JJ. Association between parathyroid hormone levels and inflammatory markers among US adults. Mediators Inflamm. (2014) 2014:709024. doi: 10.1155/2014/7 09024

30. Horst OV, Horst JA, Samudrala R, Dale BA. Caries induced cytokine network in the odontoblast layer of human teeth. BMC Immunol. (2011) 12:1-13. doi: 10.1186/1471-2172-12-9

31. Gornowicz A, Bielawska A, Bielawski K, Grabwska SZ, Wojcicka A, Zalewska M, et al. Pro-inflammatory cytokines in saliva of adolescents with dental caries disease. Ann Agric Environ Med. (2012) 19:711-6.

32. Reis CLB, Barbosa MCF, Machado BMDSM, Baratto SSP, de Lima DC, Paza AO, et al. Genetic polymorphisms in interleukin-6 and interleukin-1-beta were associated with dental caries and gingivitis. Acta Odontol Scand. (2021) 79:96-102. doi: 10.1080/00016357.2020.17 88722

33. Almoudi MM, Hussein AS, Hassan MIA, Schroth RJ. Dental caries and vitamin D status in children in Asia. Pediatr Int. (2019) 61:327-38. doi: $10.1111 /$ ped.13801
34. Bener A, Al Darwish MS, Hoffmann GF. Vitamin D deficiency and risk of dental caries among young children: a public health problem. Indian J Oral Sci. (2013) 4:75-82. doi: 10.4103/0976-6944.119937

35. Pandey P, Reddy NV, Rao VAP, Saxena A, Chaudhary CP. Estimation of salivary flow rate, $\mathrm{pH}$, buffer capacity, calcium, total protein content and total antioxidant capacity in relation to dental caries severity, age and gender. Contemp Clin Dent. (2015) 6:S65-71. doi: 10.4103/0976-237X.152943

36. Navarro CLA, Grgic O, Trajanoska K, van der Tas, JT, Rivadeneira F, et al. Associations between prenatal, perinatal, and early childhood vitamin D status and risk of dental caries at 6 years. J Nutr. (2021) 151:nxab075. doi: $10.1093 /$ jn/nxab075

37. Khundmiri SJ, Murray RD, Lederer E. PTH and vitamin D. Compr Physiol. (2016) 6:561-601. doi: 10.1002/cphy.c140071

38. Khan M, Jose A, Sharma S. Physiology, Parathyroid Hormone. (2021). Available online at: https://www.ncbi.nlm.nih.gov/books/NBK499940/ (accessed April 29, 2021).

39. Küchler EC, Reis CLB, Marañón-Vásquez G, Nelson-Filho P, Matsumoto MAN, Stuani MBS, et al. Parathyroid hormone gene and genes involved in the maintenance of vitamin D levels association with mandibular retrognathism. J Person Med. (2021) 11:369. doi: 10.3390/jpm11050369

Conflict of Interest: The authors declare that the research was conducted in the absence of any commercial or financial relationships that could be construed as a potential conflict of interest.

Publisher's Note: All claims expressed in this article are solely those of the authors and do not necessarily represent those of their affiliated organizations, or those of the publisher, the editors and the reviewers. Any product that may be evaluated in this article, or claim that may be made by its manufacturer, is not guaranteed or endorsed by the publisher.

Copyright (c) 2021 Reis, Barbosa, de Lima, Madalena, Baratto-Filho, Proff, de Oliveira, Paddenberg, Küchler and Kirschneck. This is an open-access article distributed under the terms of the Creative Commons Attribution License (CC BY). The use, distribution or reproduction in other forums is permitted, provided the original author(s) and the copyright owner(s) are credited and that the original publication in this journal is cited, in accordance with accepted academic practice. No use, distribution or reproduction is permitted which does not comply with these terms. 